\title{
Author Correction: Donkey genomes provide new insights into domestication and selection for coat color
}

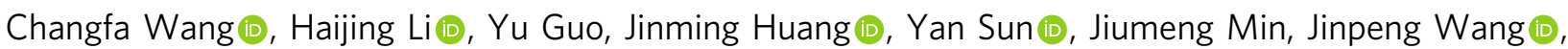
Xiaodong Fang, Zicheng Zhao, Shuai Wang, Yanlin Zhang, Qingfeng Liu, Qiang Jiang, Xiuge Wang, Yijun Guo, Chunhong Yang, Yinchao Wang, Fang Tian, Guilong Zhuang, Yanna Fan, Qican Gao, Yuhua Li, Zhihua Ju, Jianbin Li, Rongling Li, Minghai Hou, Guiwen Yang, Guiqin Liu, Wenqiang Liu, Jiao Guo, Shanshan Pan, Guangyi Fan, Wei Zhang, Ruitao Zhang, Jie Yu, Xinhao Zhang, Qi Yin, Chuanliang Ji, Yuanchun Jin, Guidong Yue, Mei Liu, Jiake Xu (D), Shimin Liu, Jordi Jordana (D), Antonia Noce (D), Marcel Amills (D), Dong Dong Wu (D), Shuaicheng Li (D), Xiangshan Zhou \& Jifeng Zhong (D)

Correction to: Nat. Commun. https://doi.org/10.1038/s41467-020-19813-7, published online 8 December 2020.

The original version of this Article contained an error in the author contributions, which incorrectly omitted the following: 'J.W. led the experiments to study the genetic mechanism underlying the emergence of the non-Dun coat colors of donkeys, including performing RNA-seq of croup skin samples of Dun and non-Dun donkeys, performing the immunohistochemistry and immunofluorescence assays against donkey TBX3 protein and bioinformatics analysis of the $1 \mathrm{bp}$ deletion downstream the TBX3 gene. J.W. also contributed to the plotting of Figures'.

The original version of this Article also contained an error in the author affiliations. The affiliation of Antonia Noce with LeibnizInstitute for Farm Animal Biology (FBN), Dummerstorf 18196, Germany, was inadvertently omitted.

These have now been corrected in both the PDF and HTML versions of the Article.

Published online: 26 January 2021

Open Access This article is licensed under a Creative Commons Attribution 4.0 International License, which permits use, sharing, adaptation, distribution and reproduction in any medium or format, as long as you give appropriate credit to the original author(s) and the source, provide a link to the Creative Commons license, and indicate if changes were made. The images or other third party material in this article are included in the article's Creative Commons license, unless indicated otherwise in a credit line to the material. If material is not included in the article's Creative Commons license and your intended use is not permitted by statutory regulation or exceeds the permitted use, you will need to obtain permission directly from the copyright holder. To view a copy of this license, visit http://creativecommons.org/licenses/by/4.0/.

(C) The Author(s) 2021 